\title{
Introduction to Gendering and Sexualities
}

\author{
Shahana Rasool ${ }^{1}$ (D)
}

Accepted: 21 July 2021 / Published online: 21 August 2021

(c) The Author(s), under exclusive licence to Springer Science+Business Media, LLC, part of Springer Nature 2021

The terrain of both gender and sexuality are complex and increasingly interrogated and deconstructed domains. I have deliberately used the word 'gendering' rather than gender in the title because of the way in which gender is and continues to be constructed and re-constructed by individuals, couples, families and communities. Gendering and Sexuality are constantly being mediated and "constructed through and within other relations of power such a class, 'race'/ethnicity or imperialism/ colonialism" and ongoing coloniality [1]. Assumptions about sex, heteronormativity, gender binaries are increasingly being contested, re-articulated and re-imagined. It is within this ever evolving and growing field that The International Conference on Gender and Sexuality $(G \& S)$ aims to explore, highlight, reflect on, engage with, develop and lead. Hence, challenging and re-imagining historical assumptions and constructions of gendering and sexualities and how they manifest in people's lives and communities are critical to explore and understand. This special edition is based on paper presentations from the G\&S conferences. To tackle the problems of gender inequality, gender-based violence, misogyny and/or heteronormativity effectively or firmly, more spaces for serious intellectual engagement and the opening of conversations, amongst scholars, practitioners, policy makers and most importantly those of us who embody various gender identities and sexualities across all divides and disciplines, is needed. The G\&S conference opens the space to share views and ideas and consider values and experiences to build strong relationships among delegates. The conference is aimed at achieving mutual objectives for transforming the way genders and sexualities are perceived and constructed, through creating collaborative initiatives for the expansion of theorising about and harnessing innovative practice in the fields of gender and sexuality. It is also a space for understanding and theorising about how these two fields intersect for the co-creation of theories and practices that are appropriate and ground-breaking.

The contribution to knowledge building in the domains of gendering and sexualities is couched in the exciting and ground-breaking work of young and emerging scholars both during the conference and in these and other publications. The work

Shahana Rasool

shahanar@uj.ac.za

1 University of Johannesburg, Johannesburg, South Africa 
of young, free thinkers who are unafraid to enter new domains of knowledge, being and doing [2] are reflected in the articles of this issue. Orth in her analysis of social media posts on Facebook develops a powerful argument on how rape culture manifests in South African societies. Analysis of social media is an important location for understanding unmediated social views, social interactions and mainstream opinions on important social, political and economic issues [4]. It often highlights contested terrains and reflects deep fissures on social, political and economic matters. At the same time, it has also been an effective domain for political organising and transformative education on issues of gendering and sexualities.

The sex trade, sex work, transactional sex are not uncommon across the world, yet individuals who sell sex remain highly stigmatised, discriminated and vulnerable. The article by Sternerson et al., highlights the heterogeneity of individuals who sell sex in Thailand and thus account for the experiences of not only women, but male and transgender individuals who sell sex. This study also considers foreigner attitudes towards women, men and non-binary individuals who sell sex, and shows how these attitudes are influenced by both gender and previous engagement of these individuals themselves in transactional sex. These types of studies are critical to inform policy and practice that creates safer environments for individuals who sell sex and increases their access to resources.

Discourses and beliefs about vulnerable groups have emerged as central to both professional and community responses to individuals, at risk of violence and stigmatisation as evidenced in the previous two articles. The third article in this special edition also highlights the role of the discourse of "the whole story" in the response of informal networks to survivors of women abused by men. The article by Mwatsiya and Rasool shows how violence against women in intimate partner relationships is justified under certain conditions and particularly when women violate expected gendered norms, especially by male support systems. Violence against women was not in itself condemned by many of the male participants, if they felt that the women concerned violated established socio-cultural norms. This article again highlights the necessity to work in communities to challenge gender norms and stereotypes that allow for violence against women to flourish and be sustained [7].

The gendered nature of violence in situations of conflict is another area of important consideration. Rape as a weapon of war is evident throughout history and the impacts are wide-ranging [6]. Habib specifically documents the vulnerabilities of disadvantaged women who are living in Kashmir. She reiterates the importance of having the voices of vulnerable women heard, so that they can tell their stories and the impact of violence and war on their lives and livelihoods. The sense of helplessness and lasting impacts of violence on their lives left an inedible mark on my psyche. Issues of access to care and services that are gender sensitive and appropriate remain a concern for these Mohajir women even post- conflict. Nevertheless, these women find ways to carve new future for themselves and their families. This article provides some valuable options for intervention including education, which could be implemented to assist Mohajir women and other women post-conflict on their journeys to recovery.

Education has been shown internationally to be a game changer, and critical for development [3]. Sharma and Dev [5], point out that policy interventions related to 
education were most likely to have multiplier effects on progress for all development goals. The article by Iddy et al. points to the disjuncture between policy on girl child education and practice in Tanzania. Whilst it is clear that both at international and national levels, critical policies have been developed to facilitate the education of the girl child. Not enough work is being done at community level with regards to the daily obstacles and challenges that girls face in accessing and engaging in education. Hence, policies alone are not enough, grassroots work that engages sociocultural and religious attitudes and practices that impact on the education of the girl child is essential.

Evidence of the disjuncture between laws and practices is again highlighted by Haffejee in the final article of this edition. The very important narrative of a transgender youth from a resource poor rural community in South Africa, shows how resilience in the face of discrimination, violence and abuse, is necessary even in a context of progressive laws. There remains a multitude of systemic obstacles for non-binary communities in accessing health care and other resources that are gender affirming and responsive. The role of religions, cultural practices, and gender norms in perpetuating discrimination and abuse was evident in Zee's experiences. Nevertheless, Haffejee contends that "Zee is neither consistently resilient nor is she in constant distress." In essence the binary is not useful in considering adversity and resilience, as these co-exist. Despite high levels of resilience, these various systems contribute to the Othering and violation of queer bodies and identities. Nevertheless, the ongoing adversity faced by queer bodies can often be mitigated by strong support systems.

Violence seems to be a core themes that emerged throughout the various papers in this edition:- violence against women due to ethnic conflict, violence against women due to cultural norms and stereotypes, violence in intimate partner relationships, violence against queer people, violence against sex workers, and violence experienced by school-girls. Hence, any analysis of gendering and sexuality needs to recognise that these experiences and identities are mediated through various forms of historical and contemporary power structures. Socio-cultural context and norms are also critical for navigating gendering and sexualities. Policies and laws are often not enough to address these violations, when community attitudes and responses are still enmeshed in stereotyped and remain limited notions of gender and sexualities. These contexts and the informal networks that operate within them can on the one hand be a source of increased adversity. On the other hand, they could challenge entrenched notions of gender and sexuality and enable resilience and transformation. Community education and working with socio-cultural norms and practices that contribute to discrimination, violence and marginalisation need to be challenged and re-constructed. In conclusion, this ever-evolving field of gendering and sexualities has over the years pushed many boundaries, met with resistance by some and enthusiasm by others, but will nevertheless be a space for re-creating, imagining and transformation. 


\section{References}

1. Beasley, C. (2005). Gender and sexuality: Critical theories critical thinkers. Sage.

2. Dastile, N. P., \& Ndlovu-Gatsheni, S. J. (2013). Power, knowledge and being: Decolonial combative discourse as a survival kit for Pan-Africanists in the 21st century. Alternation, 20(1), 105-134.

3. Rasool, S. (2017). Gender and development. In J. Midgley \& M. Pawar (Eds.), Future directions for social development (pp. 119-139). Palgrave.

4. Social Media Research Group. (2016) Using social media for social research: An introduction. Social Science in Government. https://assets.publishing.service.gov.uk/government/uploads/system/ uploads/attachment_data/file/524750/GSR_Social_Media_Research_Guidance_-_Using_social_ media_for_social_research.pdf

5. Sharma, M., \& Dev, K. (2017). Role of education in achieving millennium development goals. IOSR Journal of Humanities and Social Science, 22(11), 18-23.

6. Wirtz, A. L., Pham, K., Glass, N., et al. (2014). Gender-based violence in conflict and displacement: Qualitative findings from displaced women in Colombia. Conflict and Health, 8, 10.

7. Rasool, S. (2012). Abused Women's Experiences with Social Workers and Shelters. The Social Work Practitioner - Researcher, 24(1).

Publisher's Note Springer Nature remains neutral with regard to jurisdictional claims in published maps and institutional affiliations. 